\title{
Novel Efficient Bioprocessing of Marine Chitins into Active Anticancer Prodigiosin
}

\author{
Van Bon Nguyen ${ }^{1,2}{ }^{\infty}$, Shan-Ping Chen ${ }^{3}$, Thi Hanh Nguyen ${ }^{4}$, Minh Trung Nguyen ${ }^{5}{ }^{(D)}$, \\ Thi Thanh Thao Tran ${ }^{5}$, Chien Thang Doan ${ }^{5}{ }^{(\mathbb{C}}$, Thi Ngoc Tran ${ }^{5}$, Anh Dzung Nguyen ${ }^{4}{ }^{(\mathbb{C}}$, \\ Yao-Haur Kuo ${ }^{6}$ and San-Lang Wang $3,7, * \mathbb{D}$ \\ 1 Division of Computational Mathematics and Engineering, Institute for Computational Science, \\ Ton Duc Thang University, Ho Chi Minh City 700000, Vietnam; nguyenvanbon@tdtu.edu.vn \\ 2 Faculty of Applied Sciences, Ton Duc Thang University, Ho Chi Minh City 700000, Vietnam \\ 3 Department of Chemistry, Tamkang University, New Taipei City 25137, Taiwan; peter831119@gmail.com \\ 4 Institute of Biotechnology and Environment, Tay Nguyen University, Buon Ma Thuot 630000, Vietnam; \\ nguyenhanh2208.tn@gmail.com (T.H.N.); nadzungtaynguyenuni@yahoo.com.vn (A.D.N.) \\ 5 Department of Science and Technology, Tay Nguyen University, Buon Ma Thuot 630000, Vietnam; \\ nguyenminhtrung2389@gmail.com (M.T.N.); thanhthaotnu@gmail.com (T.T.T.T.); \\ doanthng@gmail.com (C.T.D.); tranngoctnu@gmail.com (T.N.T.) \\ 6 Division of Chinese Materia Medica Development, National Research Institute of Chinese Medicine, \\ Taipei 11221, Taiwan; kuoyh@nricm.edu.tw \\ 7 Department of Chemical and Materials Engineering, Tamkang University, New Taipei City 25137, Taiwan \\ * Correspondence: sabulo@mail.tku.edu.tw; Tel.: +886-2-2621-5656; Fax: +886-2-2620-9924
}

Received: 6 December 2019; Accepted: 20 December 2019; Published: 23 December 2019

check for updates

\begin{abstract}
Marine chitins (MC) have been utilized for the production of vast array of bioactive products, including chitooligomers, chitinase, chitosanase, antioxidants, anti-NO, and antidiabetic compounds. The aim of this study is the bioprocessing of MC into a potent anticancer compound, prodigiosin (PG), via microbial fermentation. This bioactive compound was produced by Serratia marcescens TKU011 with the highest yield of $4.62 \mathrm{mg} / \mathrm{mL}$ at the optimal conditions of liquid medium with initial $\mathrm{pH}$ of 5.65-6.15 containing $1 \% \alpha$-chitin, $0.6 \%$ casein, $0.05 \% \mathrm{~K}_{2} \mathrm{HPO}_{4}$, and $0.1 \% \mathrm{CaSO}_{4}$. Fermentation was kept at $25^{\circ} \mathrm{C}$ for $2 \mathrm{~d}$. Notably, $\alpha$-chitin was newly investigated as the major potential material for PG production via fermentation; the salt $\mathrm{CaSO}_{4}$ was also found to play the key role in the enhancement of PG yield of Serratia marcescens fermentation for the first time. PG was qualified and identified based on specific UV, MALDI-TOF MS analysis. In the biological activity tests, purified PG demonstrated potent anticancer activities against A549, Hep G2, MCF-7, and WiDr with the $\mathrm{IC}_{50}$ values of 0.06, $0.04,0.04$, and $0.2 \mu \mathrm{g} / \mathrm{mL}$, respectively. Mytomycin C, a commercial anti-cancer compound was also tested for comparison purpose, showing weaker activity with the $\mathrm{IC}_{50}$ values of $0.11,0.1,0.14$, and $0.15 \mu \mathrm{g} / \mathrm{mL}$, respectively. As such, purified PG displayed higher 2.75-fold, 1.67-fold, and 3.25-fold efficacy than Mytomycin C against MCF-7, A549, and Hep G2, respectively. The results suggest that marine chitins are valuable sources for production of prodigiosin, a potential candidate for cancer drugs.
\end{abstract}

Keywords: $\alpha$-Chitin; prodigiosin; anti-tumors; Serratia marcescens; bioprocessing

\section{Introduction}

Chitin, an abundant material, has been widely produced from fishery processing byproducts. Of the natural chitin-containing materials, shrimp shells, squid pens, and crab shells have the highest chitin content [1], and as such, are used for chitin production. Chitin and its derivatives display great economic value thanks to their versatile activities and potential biotechnological 
applications, and chitin-containing materials have been reported to be used for the production of a vast array of bioactive products, such as exopolysaccharides [2-4], chitooligomers [5], antioxidants [6,7], biofertilizers [8] insecticidal materials [9,10], and biosorbents [11,12]. Recently, these chitin-containing materials were extensively used for the production of antidiabetic drugs [13-18]. In this study, chitinous materials were utilized for the production of prodigiosin, an active anticancer compound, via microbial fermentation.

Prodigiosin (PG), a red pigment is a typical alkaloid constituent produced by several bacterial genus, Serratia marcescens and some other Gram-negative bacterial strains [19]. PGs have been recognized as bioactive bacterial metabolites with vast reported valuable bioactivities, including antibacterial, cytotoxic, antifungal, algicidal, antiprotozoal, antimalarial, antiproliferative, anticancer [19-22], antioxidant, and immunosuppressant [23] activities. PG also has been uniquely used as a natural based dye for textiles and olefins [24].

Due to the wild range of unique applications of PG, the production studies on this bioactive compound have been received with great interest $[13,24]$, and many types and selective media have been investigated for PG production via microbial fermentation, such as a medium containing $2 \%$ sodium oleate [25], maltose broth, nutrient broth containing sesame seeds, peptone glycerol broth [26], nutrient broth, nutrient broth with $0.5 \%$ maltose or $0.5 \%$ glucose, powdered peanut seed broth [27], corn steep mannitol medium, mannitol medium, corn steep medium, Cassava waste mannitol medium, cassava waste medium, and luria bertani glucose medium [23]. For low cost production of PG, we established the PG production from marine chitinous wastes [9-11]. In these studies, various marine chitinous materials, including crab shells, shrimp shells, shrimp heads and squid pens were used as the sole carbon/nitrogen source; squid pens were found to be the most effective material for PG production by S. marcescens. However, numerous scientific parameters were not investigated in our previous studies, such as the kind of marine chitin $(\alpha$ or $\beta)$, protein sources, chitin/protein ratio, and supplementary minerals for the best PG productivity production by $S$. marcescens. All those previously unknown items were newly investigated in this study, and the PG produce from the medium containing marine chitin was also evaluated for its effect on four cancerous cell lines-A549, Hep G2, MCF-7, and WIDR-in this report.

\section{Results and Discussion}

\subsection{New Records of Marine $\alpha$-Chitin as the Potential Carbon Source for Prodigiosin Synthesis by Serratia marcescens}

Carbon source has been proven to play an important role in PG production via microbial fermentation [19]. In previous studies, squid pens powder (SPP) was found to be cost-effective material for the production of PG by Serratia marcescens TKU011, compared to other materials; SPP was reported to contain approximately $60 \%$ chitin and $40 \%$ protein [13]. Thus, chitin contained in SPP may prove a significant factor in PG production. To investigate the role of chitin as well as its combination with free protein in different ratios on the PG production by S. marcescens, the chitins obtained from SPP ( $\beta$-chitin) and shrimp shells ( $\alpha$-chitin) by using the method reported by Wang et al., 2006 [28] were mixed with free protein (casein) with the ratio (chitin/casein) of 7/1,6/2,5/3, 4/4, 2/6, and 1/7 (w/w) and used as the sole carbon and nitrogen source for fermentation by S. marcescens TKU011; SPP was also used as the control for comparison purpose. The results in Figure 1 show that $\beta$-chitin mixed with casein with the ratio of $2 / 6(w / w)$ give higher PG yield production $(2.73 \mathrm{mg} / \mathrm{mL})$ than that of SPP $(2.45 \mathrm{mg} / \mathrm{mL})$ fermented by $S$. marcescens TKU011, while $\alpha$-chitin mixed with free protein at the ratio of $5 / 3(w / w)$ reach the greatest PG yield production of $3.23 \mathrm{mg} / \mathrm{mL}$. In addition to the use of $\alpha$-chitin providing higher PG yield, and $\alpha$-chitin could be more abundantly obtained from vast resources (crab shells, shrimp shells, etc.) than $\beta$-chitin (mainly obtained from squid pens); thus, $\alpha$-chitin was chosen for our further investigation. Based on the recent literature review, PG has been produced by $S$. marcescens with various types of carbon/nitrogen sources [9-11,13,14,25-33]; however, very few studies report on the use of chitinous materials (squid pens) [19] as the carbon/nitrogen source for PG 
production; for the first time in this study, $\alpha$-chitin obtained from marine resources were investigated as a potent carbon source for high scale PG production via microbial fermentation.

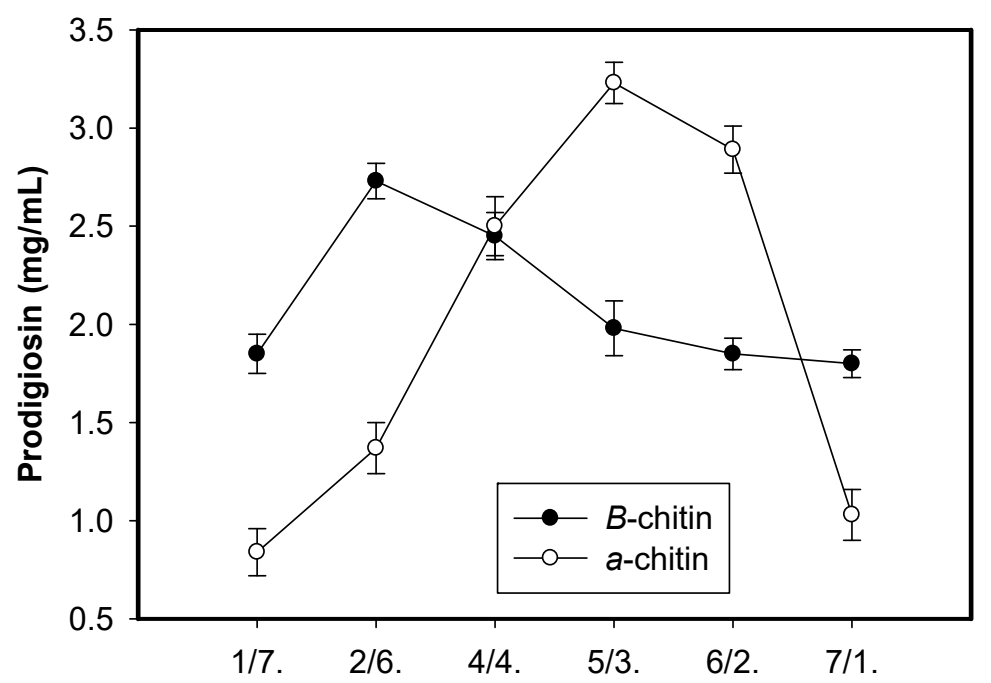

Figure 1. The effect of chitin/protein ratio. The chitin including two forms of $\alpha$-chitin and $\beta$-chitin were mixed with free protein (casein) with six ratios of $1 / 7,2 / 6,4 / 4,5 / 3,6 / 2$, and $7 / 1(w / w)$ and used as the sole carbon and nitrogen source with the concentration of $1.5 \%(w / v)$. The fermentation was performed at the conditions at $30^{\circ} \mathrm{C}$ in $1 \mathrm{~d}$, and then at $25^{\circ} \mathrm{C}$ in next $2 \mathrm{~d}$, shaking speed of $150 \mathrm{rpm}$, and a ratio volume of medium: flask of 1:2.5 (v/v).

For the comparison of the PG producing by different $S$. marcescens strains, a total four strains including S. marcescens TKU011, S. marcescens CC17, S. marcescens TNU01, and S. marcescens TNU02 were conducted for fermentation. As shown in the Table 1, S. marcescens TKU01, S. marcescens TNU01, and S. marcescens TNU02 showed their same level in PG production with the PG yield of $325-335 \mathrm{mg} / 100 \mathrm{~mL}$, and $236-243 \mathrm{mg} / 100 \mathrm{~mL}$ when the medium contained newly designed $\mathrm{C} / \mathrm{N}$ source $(0.94 \% \alpha$-chitin and $0.56 \%$ Casein), and $1.5 \%$ squid pens, respectively. S. marcescens CC17 demonstrated the lowest production of PG yield.

Table 1. Comparison of the prodigiosin yield $(\mathrm{mg} / 100 \mathrm{~mL})$ produced by different Serratia marcescens strains.

\begin{tabular}{ccc}
\hline PG - Producing Strains & \multicolumn{2}{c}{ C/N Source } \\
\hline & $\mathbf{0 . 9 4 \%} \boldsymbol{\alpha}$-Chitin $+\mathbf{0 . 5 6 \%}$ Casein & $\mathbf{1 . 5 \%}$ Squid Pens \\
\hline S. marcescens TKU011 & $335 \pm 14.4^{\mathrm{a}}$ & $243 \pm 24.8^{\mathrm{b}}$ \\
\hline S. marcescens CC17 & $227 \pm 2.93^{\mathrm{b}}$ & $150 \pm 5.77^{\mathrm{c}}$ \\
\hline S. marcescens TNU01 & $329 \pm 16.7^{\mathrm{a}}$ & $240 \pm 17.3^{\mathrm{b}}$ \\
\hline S. marcescens TNU02 & $325 \pm 14.4^{\mathrm{a}}$ & $236 \pm 20.8^{\mathrm{b}}$ \\
\hline No bacteria & - & -
\end{tabular}

Means of prodigiosin yield $(\mathrm{mg} / 100 \mathrm{~mL})$ values with the same letter are not significantly different based on Duncan's multiple range test $(\mathrm{alpha}=0.01) . \mathrm{CV} \%=4.271394$. $(-)$ : no prodigiosin was detected.

To date, PG has been produced from many carbon sources with multiple designed media [9-11,13, 14,25-33]. As summarized in Table 2, the designed medium gave the PG productivity in the scale of 0 up to around $200(\mathrm{mg} / 100 \mathrm{~mL})$. With the medium containing $0.94 \% \alpha$-chitin $+0.56 \%$ Casein, PG produced by $S$. marcescens TKU011 strain reached $335(\mathrm{mg} / 100 \mathrm{~mL})$. However, two previous studies reported that with $2.0 \%$ sesame seed [26] and the medium containing $6.97 \mathrm{~g} / \mathrm{L}$ of peanut powder, $11.29 \mathrm{~mL} / \mathrm{L}$ of olive oil and $16.02 \mathrm{~g} / \mathrm{L}$ of beef extract [33] even reached the PG yield of 1668 and $1362.2 \mathrm{mg} / 100 \mathrm{~mL}$, 
respectively. These are cases with 4.979-fold and 4.066-fold higher yield than PG yield produced by S. marcescens TKU011 in this study. In these above cited reports [26,33], the PG-producing bacteria may be unique strains and the qualification of PG in these studies were not described in detail.

Table 2. Comparison of the prodigiosin yield produced by S. marcescens in different reports.

\begin{tabular}{|c|c|c|c|}
\hline PG - Producing Strains & C/N Source & Prodigiosin $(\mathrm{mg} / \mathbf{1 0 0 m L})$ & Reference \\
\hline S. marcescens TKU011 & $0.94 \% \alpha$-chitin $+0.56 \%$ Casein & 335 & This study \\
\hline S. marcescens TKU011 & $1.5 \%$ squid pens & 97.8 & [9] \\
\hline S. marcescens TKU011 & $1.5 \%$ peanut powder & 116.8 & [9] \\
\hline S. marcescens TKU011 & $1.0 \%$ shrimp shells powders & 19 & [9] \\
\hline S. marcescens TKU011 & $1.0 \%$ crab shells powders & 11 & [9] \\
\hline S. marcescens TKU011 & $1.0 \%$ shrimp heads powders & 3 & [9] \\
\hline S. marcescens TKU011 & $1.5 \%$ squid pens & 248 & [28] \\
\hline S. marcescens & $2.0 \%$ peanut seed & 387.5 & [26] \\
\hline S. marcescens & $2.0 \%$ peanut oil & 289 & [26] \\
\hline S. marcescens & $2.0 \%$ sesame seed & 1668 & [26] \\
\hline S. marcescens & $2.0 \%$ sesame oil & 100.6 & [26] \\
\hline S. marcescens & $2.0 \%$ copra seed & 194 & [26] \\
\hline S. marcescens & $2.0 \%$ coconut oil & 142 & [26] \\
\hline S. marcescens $\mathrm{SM} \Delta \mathrm{R}$ & $\begin{array}{l}\text { Modified Luria-Bertani broth, } 6.0 \% \\
\text { sunflower oil }\end{array}$ & 79 & [29] \\
\hline S. marcescens SS-1 & $5 \mathrm{~g} / \mathrm{L}$ yeast extract as sole $\mathrm{N} / \mathrm{C}$ source & 69 & {$[30]$} \\
\hline S. marcescens Nima & $2 \%$ tryptone/glycerol (1/1) & 12.5 & [31] \\
\hline S. marcescens Nima & $\begin{array}{l}100 \text { mM 3-[N-morpholino]- } \\
\text { ethanesulphonic acid }\end{array}$ & 47.5 & {$[32]$} \\
\hline S. marcescens FZSF02 & $\begin{array}{c}6.97 \mathrm{~g} / \mathrm{L} \text { of peanut powder, } 11.29 \mathrm{~mL} / \mathrm{L} \\
\text { of olive oil and } 16.02 \mathrm{~g} / \mathrm{L} \text { of beef } \\
\text { extract }\end{array}$ & 1362.2 & [33] \\
\hline S. marcescens FZSF02 & $1 \%$ Soya peptone & 117.4 & [33] \\
\hline S. marcescens FZSF02 & 1\% Tryptone & 35.3 & [33] \\
\hline S. marcescens FZSF02 & $1 \%$ Yeast extract & 38.02 & [33] \\
\hline S. marcescens FZSF02 & $1 \%$ Fish meal & 0 & [33] \\
\hline S. marcescens FZSF02 & $1 \%$ Soybean powder & 0 & [33] \\
\hline S. marcescens FZSF02 & $1 \%$ Corn steep liquor & 0 & [33] \\
\hline
\end{tabular}

\subsection{Optimization of Culture Conditions for Enhancement of Prodigiosin Production by Serratia marcescens}

To investigate the effect of C/N sources on PG production by $S$. marcescens TKU011, some chitinous materials, including chitosan (a derivative of chitin), $N$-acetyl-glucosamine (monomer of chitin), glucosamine (mono of chitosan), and some other carbon sources, such as cellulose and starch, were used for fermentation. As shown in Figure 2a, among various tested carbon sources, $\alpha$-chitin displayed the most suitable substrate for PG production by S. marcescens with the greatest yield of $3.21 \mathrm{mg} / \mathrm{mL}$, followed by its monomer $N$-acetyl-glucosamine with the PG yield production of $1.81 \mathrm{mg} / \mathrm{mL}$, and all other tested carbon source give low yield PG production $(\leq 0.96 \mathrm{mg} / \mathrm{mL})$. Thus, $\alpha$-chitin was chosen as an excellent substrate for further investigation. To further investigate the effect of the combination of $\alpha$-chitin and free protein source, a total of five protein sources-beef extract, casein, nutrient broth, yeast extract, and peptone-were combined with $\alpha$-chitin used as sole $\mathrm{C} / \mathrm{N}$ source for 
fermentation by Serratia marcescens to produce PG. The experimental results in Figure $2 b$ showed that the combination of casein and $\alpha$-chitin gave a significantly higher yield of PG $(3.31 \pm 0.142 \mathrm{mg} / \mathrm{mL})$ than other combinations $(\leq 1.73 \pm 0.166 \mathrm{mg} / \mathrm{mL})$; casein was chosen for combination with $\alpha$-chitin and used as the sole $\mathrm{C} / \mathrm{N}$ source in our nest experiments. Casein was also found to be a suitable nitrogen source for producing PG with high level yield in several previous studies, such as maltose/casein and sucrose/casein with ratio 1/1 leading to PG yield production of 2.354 and $3.12 \mathrm{mg} / \mathrm{ml}$, respectively [34]; $2 \%$ oral casein was mixed with some salts and used as the medium for fermentation to produce a high yield of PG with $4.28 \mathrm{mg} / \mathrm{mL}$ [23]. Differing from previous studies, we established the novel medium with the combination of abundant chitinous material ( $\alpha$-chitin) and casein with the ratio of $5 / 3(w / w)$. This designed medium also reached the high PGs yield of $3.21 \mathrm{mg} / \mathrm{mL}$, and as such used for next investigation.

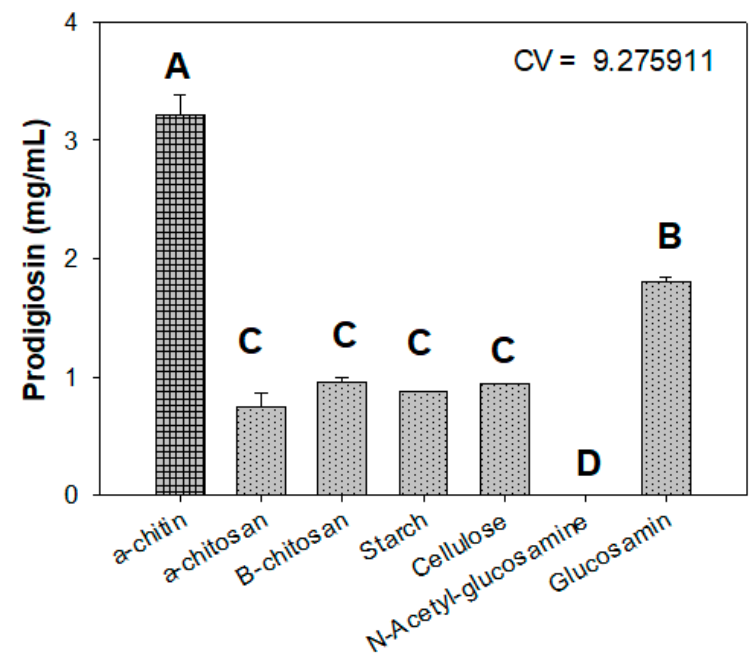

Carbonhydrate sources

(a)

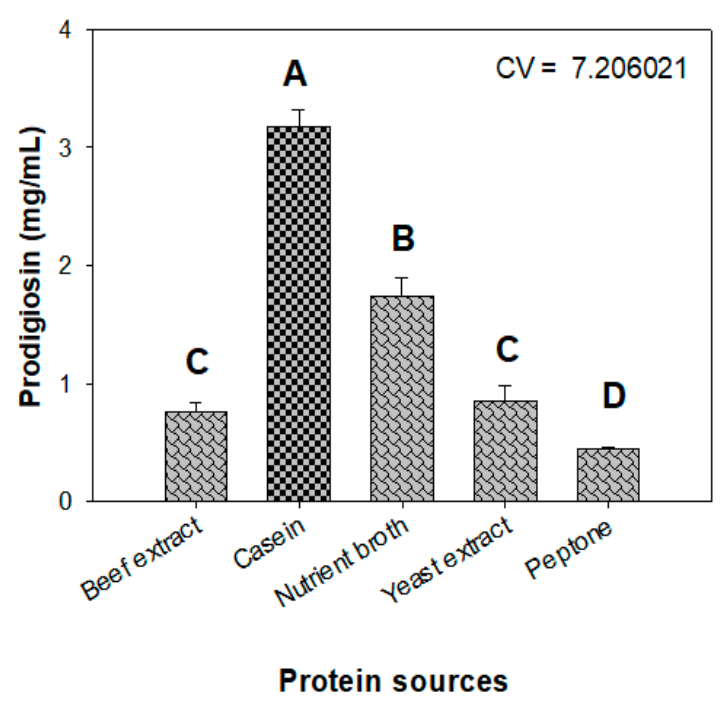

(b)

Figure 2. The effect of carbohydrate (a) and protein (b) sources on the prodigiosin production by S. marcescens TKU11. Carbohydrate and protein were mixed at the ratio of $5 / 3$ and used as the $\mathrm{C} / \mathrm{N}$ source. The culture medium contains $1.5 \% \mathrm{C} / \mathrm{N}$ source, $0.1 \% \mathrm{~K}_{2} \mathrm{HPO}_{4}$ and $0.1 \% \mathrm{FeSO}_{4}\left(\mathrm{NH}_{4}\right)_{2} \mathrm{SO}_{4}$. The fermentation was performed at the conditions at $30{ }^{\circ} \mathrm{C}$ in $1 \mathrm{~d}$, and then at $25{ }^{\circ} \mathrm{C}$ over the next $2 \mathrm{~d}$, shaking speed of $150 \mathrm{rpm}$, and a ratio volume of medium:flask of 1:2.5 (v/v). Means of prodigiosin yield $(\mathrm{mg} / 100 \mathrm{~mL})$ values with the same letter in each figure are not significantly different based on Duncan's multiple range test (alpha $=0.01)$.

Some previous studies indicated that salt ingredients in medium, especially phosphate and sulfate salts, played a vital role in enhancing the yield of PG $[9,19,35]$. As shown in Figure 3a, among various tested salts, $\mathrm{K}_{2} \mathrm{HPO}_{4}$ was found to be the most suitable phosphate salt for PG biosynthesis by S. marcescens. Further experiments investigated the optimal added $\mathrm{K}_{2} \mathrm{HPO}_{4}$ was $0.05 \%$ (Figure $3 \mathrm{~b}$ ). This result is in agreement with the previous reports $[19,36]$. This added concentration of $\mathrm{K}_{2} \mathrm{HPO}_{4}$ was used to mix with various kinds of sulfate salts, including $\mathrm{FeSO}_{4}\left(\mathrm{NH}_{4}\right)_{2} \mathrm{SO}_{4}, \mathrm{MgSO}_{4}, \mathrm{CaSO}_{4}, \mathrm{CuSO}_{4}$, $\left(\mathrm{NH}_{4}\right)_{2} \mathrm{SO}_{4}$ as the basal salt solution. $\mathrm{CaSO}_{4}$ demonstrated good effect on PG production with the highest yield of $4.32 \mathrm{mg} / \mathrm{mL}$ (Figure 3c). The final experiment (Figure 3d) found that $\mathrm{CaSO}_{4}$ added at its of $0.1 \%$ to medium is the optimal concentration. Notably, $\mathrm{CaSO}_{4}$ was newly investigated as potent salt added to significantly enhance PG production by $S$. marcescens. 


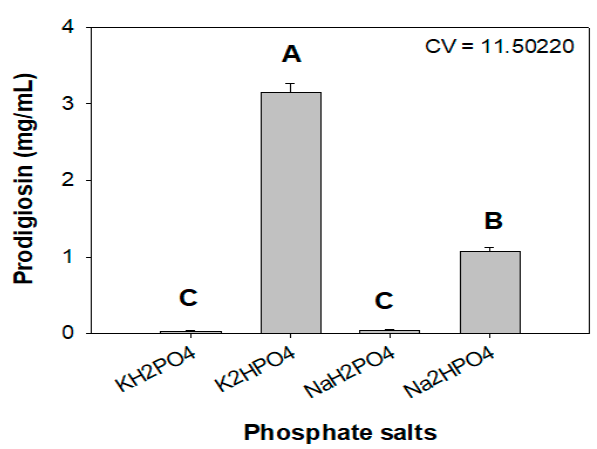

(a)

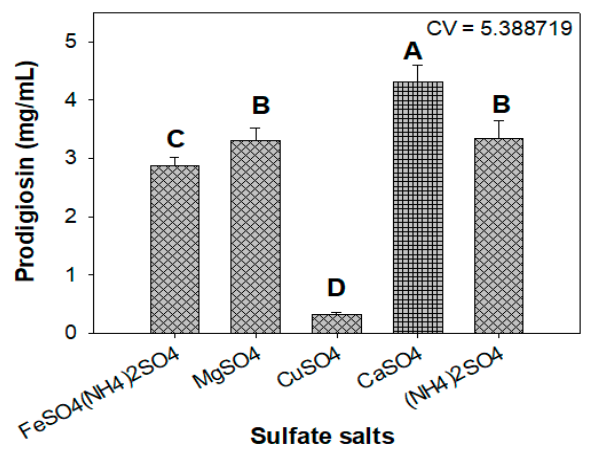

(c)

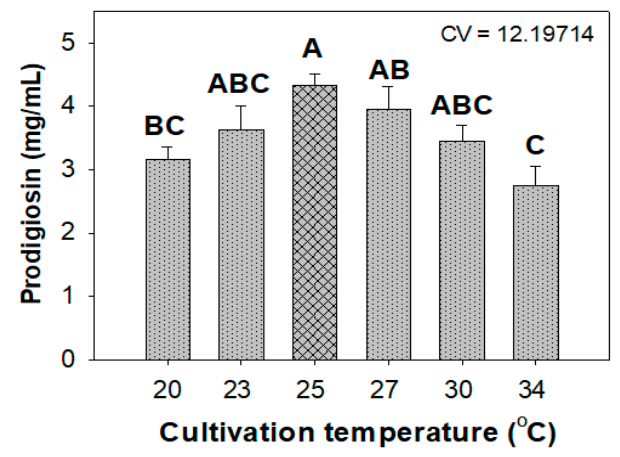

(e)

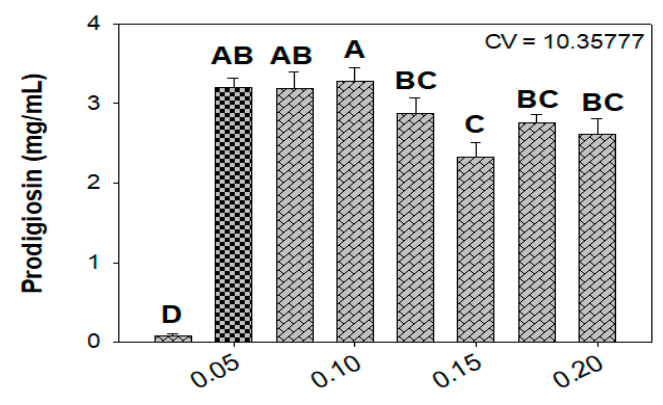

$\% \mathrm{~K} 2 \mathrm{HPO} 4$ added in culture medium

(b)

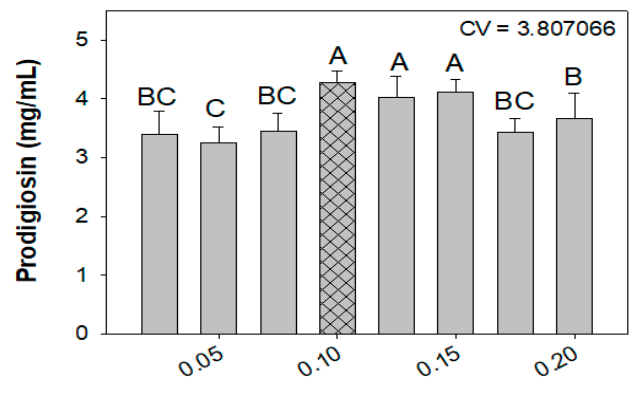

$\%$ CaSO4 added to culture medium

(d)

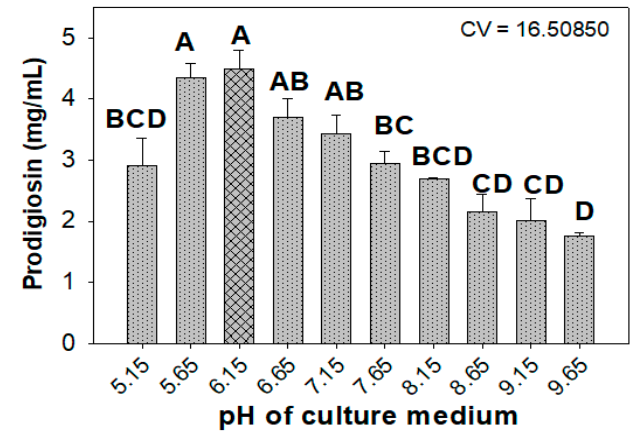

(f)

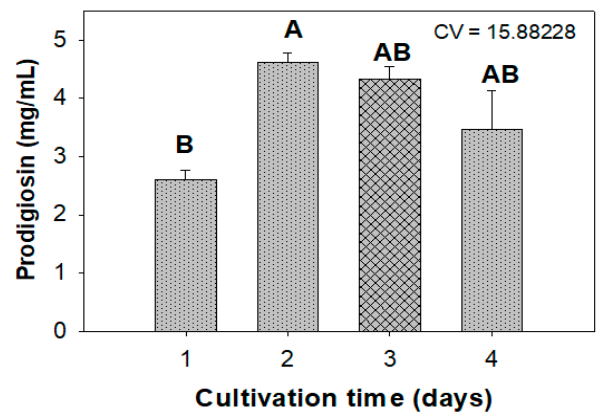

(g)

Figure 3. The effect of phosphate salts (a,b), sulfate salts (c,d), cultivation temperature (e), $\mathrm{pH}$ of culture medium (f), and cultivation time (g) on the prodigiosin production by $S$. marcescens TKU011. Medium with the combination of $\alpha$-chitin and casein with the ratio of $5 / 3(w / w)$. The culture medium containing $1.5 \% \mathrm{C} / \mathrm{N}$ source, $0.1 \% \mathrm{FeSO}_{4}\left(\mathrm{NH}_{4}\right)_{2} \mathrm{SO}_{4}(\mathbf{a}, \mathbf{b}), 0.05 \% \mathrm{~K}_{2} \mathrm{HPO}_{4}(\mathbf{c}, \mathbf{d})$. The fermentation was performed at $30{ }^{\circ} \mathrm{C}$ in $1 \mathrm{~d}$, and then at $25^{\circ} \mathrm{C}$ in the next $2 \mathrm{~d}$, shaking speed of $150 \mathrm{rpm}$, and a ratio volume of medium: flask of 1:2.5 $(\mathrm{v} / \mathrm{v})$. Means of prodigiosin yield $(\mathrm{mg} / 100 \mathrm{~mL})$ values with the same letter in each figure are not significantly different based on Duncan's multiple range test (alpha $=0.01$ ). 
To achieve maximum production of prodigiosin, some parameters, including cultivation temperature (Figure 3e), initial $\mathrm{pH}$ of medium (Figure 3f), and period of cultivation time (Figure 3g), were also investigated for their effect on PG yield produced by S. marcescens. Overall, S. marcescens TKU011 produce highest PG $(4.62 \mathrm{mg} / \mathrm{mL})$ in liquid medium with initial $\mathrm{pH}$ of $5.65-6.15$ containing $1 \%$ $\alpha$-chitin, $0.6 \%$ casein, $0.05 \% \mathrm{~K}_{2} \mathrm{HPO}_{4}$, and $0.1 \% \mathrm{CaSO}_{4}$, fermentation was kept at $25{ }^{\circ} \mathrm{C}$ for $2 \mathrm{~d}$.

\subsection{Purification and Qualification of Prodigiosin from Fermented Medium Containing $\alpha$-Chitin}

$\alpha$-chitin was mixed with casein with the ratio of $5 / 3(w / w)$ and used as the sole $\mathrm{C} / \mathrm{N}$ source at the concentration of $1.5 \%(w / v)$ for fermentation by $S$. marcescens TKU011. PG was primary extracted from the cultured broth by ethyl acetate. The PG from the cell pellet extracted with acetone was mixed with the ethyl acetate layer. After evaporation to dry crude PG, this compound was further purified via silica gel column, and then finally isolated by thin layer chromatography. The procedure is summarized in Figure 4.

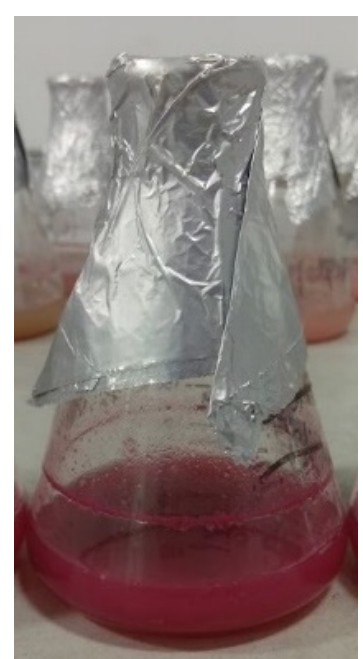

(a)

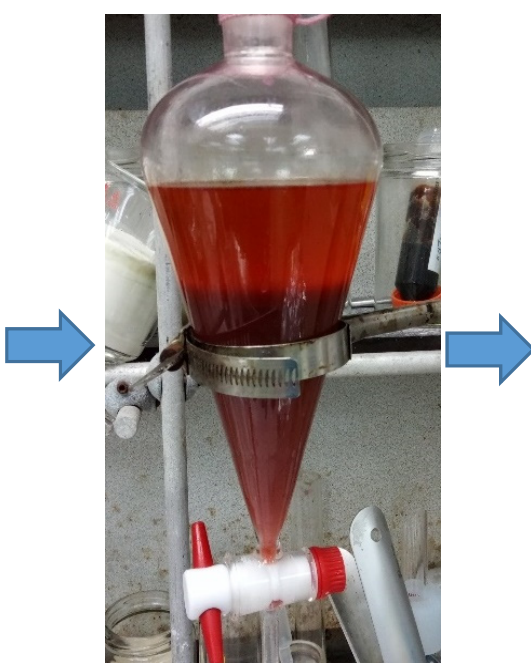

(b)

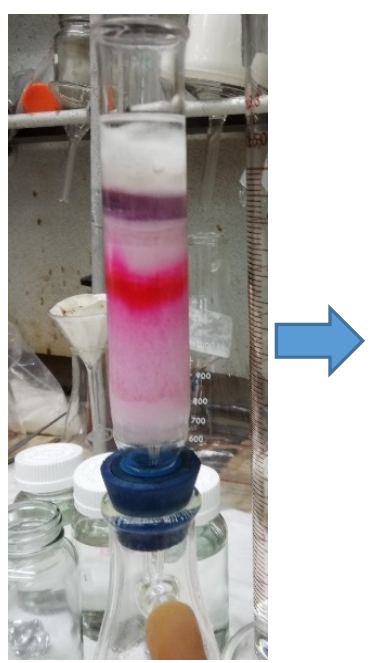

(c)

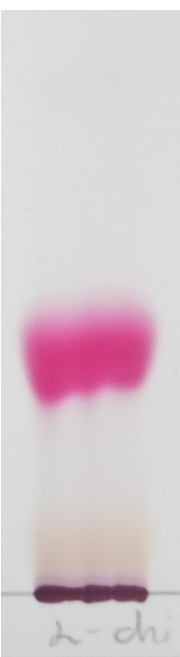

(d)

Figure 4. The purification and isolation process of prodigiosin. The culture broth containing prodigiosin (a) was extract by ethyl acetate (b). The crude prodigiosin was further separated by silica gel column

(c) and then isolated by thin layer chromatography (TLC) (d).

In our previous report [9], the S. marcescens TKU011 prodigiosin was identified via its UV absorption, molecular, and ${ }^{1} \mathrm{H}-\mathrm{NMR}$ spectrum. Due to the prodigiosin produced by the same strain, in this study, we reconfirm this purified compound by some rapid method including UV spectra and MALDI-TOF MS analysis. The purified compound demonstrated significant absorption spectroscopy at $535 \mathrm{~nm}$ (Figure 5) and the MALDI-TOF MS revealed a molecular weight of $324 \mathrm{Da}$ for the purified PG (Figure 6), which are the specific absorption weight length and molecular weight of prodigiosin $[9,33]$. 


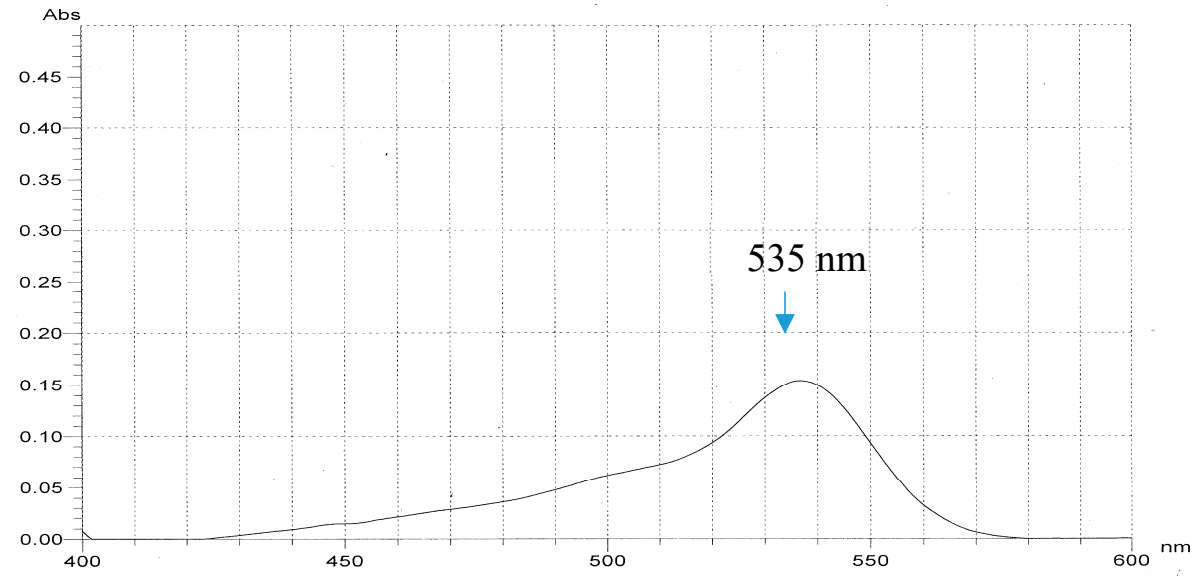

Figure 5. UV spectrum of purified prodigiosin newly biosynthesized from the novel designed substrate $(\alpha$-chitin/casein $=5 / 3)$ by $S$. marcescens TKU011.

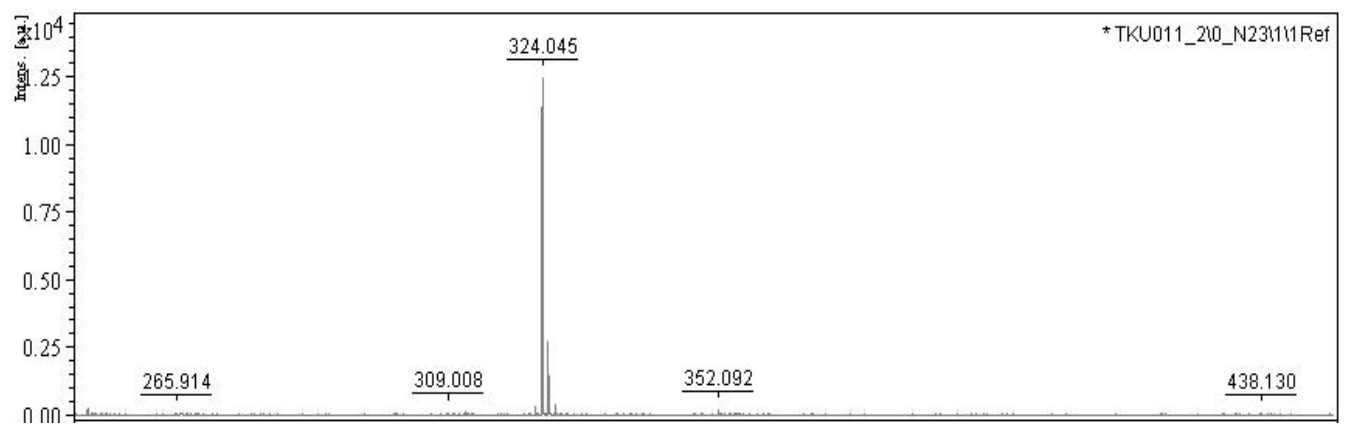

Figure 6. MALDI-TOF MS (Matrix-Assisted Laser Desorption Ionization - Time of Flight Mass Spectrometry) spectra of purified prodigiosin. 2,5-dihydroxybenzoic acid was used as a matrix in CAN-TFA- $\mathrm{H}_{2} \mathrm{O}$ solution (50/0.1/50\%, $\left.v / v / v\right)$ to separate the sample in the MALDI-TOF instrument (Bruker Daltonics, Bremen, Germany) with a nitrogen laser emitting at $337 \mathrm{~nm}$, operating in linear mode. Each spectrum of mass was calculated based on the data of around 30-50 laser shots, and external calibration with three points was used for assignment of mass [36].

\subsection{Evaluation of Inhibitory Effect of Prodigiosin against Cancerous Cell Lines Models}

Prodigiosin has been investigated for its vast biological activities, including insecticidal, antioxidant, algicidal, antimicrobial, anti-inflammatory, antimalarial, anticancer, immunomodulatory, and anti-diabetic activities [19,37]. With the aim of evaluating the prodigiosin newly synthesized in this study for potential use in anticancer drugs, prodigiosin was tested for its inhibition against some cancerous cell lines, including A549, Hep G2, MCF-7, and WiDr. As presented in Table 3, prodigiosin produced from the novel medium with the combination of $\alpha$-chitin and casein used as the $\mathrm{C} / \mathrm{N}$ source demonstrated its highly effective inhibition against all tested cancerous cell lines with great inhibition values (\%) in the range of $90.2-93.9 \%$ at the tested concentration at $10 \mu \mathrm{g} / \mathrm{mL}$. These anticancer inhibition values of prodigiosin were comparable to those of Mitomycin C, a commercial anticancer compound (91.7-94.1\%). The crude sample also showed potent activity with max inhibition values in the range of $79.4-93.2 \%$ at the concentration of at $10 \mu \mathrm{g} / \mathrm{mL}$.

The samples were tested at their concentration of $10 \mu \mathrm{g} / \mathrm{mL}$ for their anticancer activity against MCF-7 (Human breast adenocarcinoma), A549 (Human lung carcinoma), Hep G2 (Human hepatocellular carcinoma), and WiDr (Human colon adenocarcinoma). The means of inhibition (\%) with the same letter are not significantly different based on Duncan's multiple range test (alpha $=0.01$ ). $\mathrm{CV}(\%)=1.979533$. 
Table 3. Max inhibition against cancerous cell lines of prodigiosin.

\begin{tabular}{ccccc}
\hline & \multicolumn{4}{c}{ Max Inhibition Against Cancerous Cell Lines (\%) } \\
\hline MCF-7 & A549 & Hep G2 & WiDr \\
\hline Crude sample & $91.6 \pm 1.76^{\mathrm{a}, \mathrm{b}}$ & $89.2 \pm 1.43^{\mathrm{b}}$ & $93.2 \pm 2.12^{\mathrm{a}, \mathrm{b}}$ & $79.4 \pm 1.72^{\mathrm{c}}$ \\
Purified Prodigiosin & $92.5 \pm 1.4^{\mathrm{a}, \mathrm{b}}$ & $92.6 \pm 1.9^{\mathrm{a}, \mathrm{b}}$ & $93.9 \pm 2.0^{\mathrm{a}}$ & $90.2 \pm 1.12^{\mathrm{a}, \mathrm{b}}$ \\
Mitomycin C & $94.1 \pm 1.61^{\mathrm{a}}$ & $93.3 \pm 1.54^{\mathrm{a}, \mathrm{b}}$ & $91.7 \pm 1.01^{\mathrm{a}, \mathrm{b}}$ & $92.6 \pm 1.02^{\mathrm{a}, \mathrm{b}}$ \\
\hline
\end{tabular}

The samples were tested at their concentration of $10 \mu \mathrm{g} / \mathrm{mL}$ for their anticancer activity against MCF-7 (Human breast adenocarcinoma), A549 (Human lung carcinoma), Hep G2 (Human hepatocellular carcinoma), and WiDr (Human colon adenocarcinoma). The means of inhibition (\%) with the same letter are not significantly different based on Duncan's multiple range test (alpha $=0.01)$. CV $(\%)=1.979533$.

To clarify the potential effect of prodigiosin against these tested cancerous cells, the samples were diluted and tested in various concentrations; the result of anticancer activity was then calculated and presented as $\mathrm{IC}_{50}$ value. $\mathrm{IC}_{50}$ value is a concentration of sample that may reduce $50 \%$ of cancerous cells; therefore, the smallest this value of the sample, the strongest anticancer activity it displayed. As shown in Table 3, prodigiosin strongly inhibited all 4 tested cancerous cells with very low $\mathrm{IC}_{50}$ values of 0.04, 0.06, 0.04, and 0.20 against A549, Hep G2, MCF-7, and WiDr, respectively (Table 4). The anticancer activity of the purified prodigiosin is clearly higher than that of the crude sample with $\mathrm{IC}_{50}$ values in the range of $0.38-0.88 \mu \mathrm{g} / \mathrm{mL}$. Mitomycin $\mathrm{C}$ was also tested in comparison and showed its inhibition against A549, Hep G2, MCF-7 and WiDr with IC50 values of 0.11, 0.10, 0.13, and 0.10 $\mu \mathrm{g} / \mathrm{mL}$, respectively. In comparison, prodigiosin displayed significantly higher inhibition against A549, Hep G2, and MCF-7 but weaker inhibition against WiDr than Mitomycin C.

Table 4. Anticancer activities of prodigiosin.

\begin{tabular}{ccccc}
\hline & \multicolumn{4}{c}{ Inhibition Against Cancerous Cell Lines (IC50, $\mu \mathrm{g} / \mathrm{mL})$} \\
\hline MCF-7 & A549 & Hep G2 & WiDr \\
\hline Crude sample & $0.44 \pm 0.09^{\mathrm{c}, \mathrm{b}}$ & $0.46 \pm 0.01^{\mathrm{b}}$ & $0.38 \pm 0.01^{\mathrm{c}, \mathrm{b}}$ & $0.88 \pm 0.05^{\mathrm{a}}$ \\
Purified Prodigiosin & $0.04 \pm 0.01^{\mathrm{e}}$ & $0.06 \pm 0.01^{\mathrm{e}}$ & $0.04 \pm 0.01^{\mathrm{e}}$ & $0.20 \pm 0.03^{\mathrm{d}}$ \\
Mitomycin C & $0.11 \pm 0.01^{\mathrm{e}}$ & $0.10 \pm 0.01^{\mathrm{e}}$ & $0.13 \pm 0.01^{\mathrm{e}}$ & $0.10 \pm 0.01^{\mathrm{e}}$ \\
\hline
\end{tabular}

The samples were tested at their concentration range of $0.01-10 \mu \mathrm{g} / \mathrm{mL}$ for their anticancer activity against MCF-7 (Human breast adenocarcinoma), A549 (Human lung carcinoma), Hep G2 (Human hepatocellular carcinoma), and WiDr (Human colon adenocarcinoma). Means of $\mathrm{IC}_{50}(\mu \mathrm{g} / \mathrm{mL})$ values with the same letter are not significantly different based on Duncan's multiple range test (alpha $=0.01) . \mathrm{CV} \%=12.9069$.

To date, various prodigiosin compounds produced via fermentation reported anticancer activity against MCF-7 and A549. Prodigiosin was also reported showing inhibition against Hep G2 in several reports [38,39]. However, no available data report the potent inhibition of prodigiosin against human colon adenocarcinoma WiDr cell line. Specifically, the purified prodigiosin produced from marine chitin materials in the current study demonstrated high level anticancer activity. It displayed higher 2.75-, 1.67-, and 3.25-fold efficacy than commercial anticancer compounds against MCF-7, A549, and Hep G2, respectively.

Anticancer drugs have been extensively investigated for years. Commercially available anticancer drugs obtained from chemical synthesis show strong activity but result in various side effects [40]. Thus, the investigation of natural anticancer drugs has received much interest. Prodigiosin was investigated as a potent natural anticancer agent since it showed strong inhibition against a wide range of human cancer cell lines but lower toxicity toward normal cells [41]. The mechanisms of anticancer activity of prodigiosin were reported in previous studies [41-43]. Prodigiosin induces apoptosis in various human cancer cells [42], and some possible mechanisms were prosed that prodigiosin as mitogen-activated protein kinase regulators, cell cycle inhibitors, DNA cleavage agents, and $\mathrm{pH}$ modulators [43]. The results in this study contributed to announce the novel anticancer activity of prodigiosin against WiDr cell line and also reconfirmed that prodigiosin as effective anticancer agents. 


\section{Materials and Methods}

\subsection{Materials}

Serratia marcescens TKU011 was obtained from our previous study [9]. S. marcescens CC17 obtained from the previous study [44], S. marcescens TNU01 and S. marcescens TNU02 were newly isolated from the soils of Buon Ma Thuot City, Vietnam, and identified based on $16 \mathrm{~S}$ gene sequence in this study. Shrimp shell and squid pens were purchased from Fwu-Sow Industry (Taichung, Taiwan). Four cancerous cell lines-MCF-7 (Human breast adenocarcinoma), A549 (Human lung carcinoma), Hep G2 (Human hepatocellular carcinoma), and WiDr (Human colon adenocarcinoma)-were purchased from the Bioresources Collection and Research Centre (Hsinchu, Taiwan). Mitomycin C and Silicagel (Geduran ${ }^{\circledR}$ Si 60 for column chromatography, size: $0.040-0.063 \mathrm{~mm}$ ) were obtained from Sigma Chemical Co. (St. Louis City, MO, USA) and Mitsubishi Chemical Co. (Tokyo, Japan), respectively. Reagents, solvents and common chemicals were used at the highest grade available.

16S gene sequence of Serratia marcescens TNU01:

TGGCTCAGATTGAACGCTGGCGGCAGGCTTAACACATGCAAGTCGAGCGGTAGCACAGGG GAGCTTGCTCCCTGGGTGACGAGCGGCGGACGGGTGAGTAATGTCTGGGAAACTGCCTGAT GGAGGGGGATAACTACTGGAAACGGTAGCTAATACCGCATAACGTCGCAAGACCAAAGAGG GGGACCTTCGGGCCTCTTGCCATCAGATGTGCCCAGATGGGATTAGCTAGTAGGTGGGGTAA TGGCTCACCTAGGCGACGATCCCTAGCTGGTCTGAGAGGATGACCAGCCACACTGGAACTG AGACACGGTCCAGACTCCTACGGGAGGCAGCAGTGGGGAATATTGCACAATGGGCGCAAGC CTGATGCAGCCATGCCGCGTGTGTGAAGAAGGCCTTCGGGTTGTAAAGCACTTTCAGCGAG GAGGAAGGTGGTGAACTTAATACGTTCATCAATTGACGTTACTCGCAGAAGAAGCACCGGC TAACTCCGTGC.

$16 \mathrm{~S}$ gene sequence of Serratia marcescens TNU02:

CTGGCTCAGATTGAACGCTGGCGGCAGGCTTAACACATGCAAGTCGAGCGGTAGCACAGG GGAGCTTGCTCCCCTGGGTGACGAGCGGCGGACGGGTGAGTAATGTCTGGGAAACTGCCTGA TGGAGGGGGATAACTACTGGAAACGGTAGCTAATACCGCATAACGTCGCAAGACCAAAGAG GGGGACCTTCGGGCCTCTTGCCATCAGATGTGCCCAGATGGGATTAGCTAGTAGGTGGGGTA ATGGCTCACCTAGGCGACGATCCCTAGCTGGTCTGAGAGGATGACCAGCCACACTGGAACT GAGACACGGTCCAGACTCCTACGGGAGGCAGCAGTGGGGAATATTGCACAATGGGCGCAA GCCTGATGCAGCCATGCCGCGTGTGTGAAGAAGGCCTTCGGGTTGTAAAGCACTTTCAGCG AGGAGGAAGGTGGTGAACTTAATACGTTCATCAATTGACGTTACTCGCAGAAGAAGCACCG GCTAACTCCGTG C.

\subsection{Fermentation for Prodigiosin Biosynthesis by S. marcescens TKU011}

$\alpha$-chitin and $\beta$-chitin obtained from shrimp shells and squid pens were mixed with casein with 6 ratios of $1 / 7,2 / 6,4 / 4,5 / 3,6 / 2$, and $7 / 1(w / w)$ and used as the sole carbon and nitrogen source with the concentration of $1.5 \%(w / v)$ for fermentation. The medium containing $1.5 \%$ carbon and nitrogen source, $0.1 \% \mathrm{~K}_{2} \mathrm{HPO}_{4}$ and $0.1 \% \mathrm{FeSO}_{4}\left(\mathrm{NH}_{4}\right)_{2} \mathrm{SO}_{4}$ was fermented by $\mathrm{S}$. marcescens TKU011 at $30^{\circ} \mathrm{C}$ in $1 \mathrm{~d}$, and then $25^{\circ} \mathrm{C}$ over the next $2 \mathrm{~d}$, shaking speed of $150 \mathrm{rpm}$, and a ratio volume of medium:flask of 1:2.5 $(\mathrm{v} / \mathrm{v})$. $\alpha$-chitin mixed with casein at the ratio of $5 / 3(w / w)$ reached the greatest PG yield production; as such, $\alpha$-chitin/casein was used for comparison in the following experiments evaluating other carbohydrate sources (chitosan, $\mathrm{N}$-acetyl-glucosamine, glucosamine, cellulose and starch) and proteinous sources. $\alpha$-chitin/casein at the ratio of $5 / 3(w / w)$ finally proved best and was used for fermentation in the subsequent investigation, including the effect of added salts and some parameters.

The effect of phosphate salts and its optimal concentration added to culture medium on PG production: four kinds of phosphate salts- $\mathrm{KH}_{2} \mathrm{PO}_{4}, \mathrm{~K}_{2} \mathrm{HPO}_{4}, \mathrm{NaH}_{2} \mathrm{PO}_{4}$, and $\mathrm{Na}_{2} \mathrm{HPO}_{4}$-were used. The medium containing $0.1 \% \mathrm{FeSO}_{4}\left(\mathrm{NH}_{4}\right)_{2} \mathrm{SO}_{4}, 0.1 \%$ phosphate salt, and $1.5 \% \mathrm{C} / \mathrm{N}$ source were fermented at $30^{\circ} \mathrm{C}$ in $1 \mathrm{~d}$, and then at $25^{\circ} \mathrm{C}$ over the next $2 \mathrm{~d}$, shaking speed of $150 \mathrm{rpm}$, and a ratio volume of medium:flask of 1:2.5 (v/v). $\mathrm{KH}_{2} \mathrm{PO}_{4}$ was found to be the most suitable phosphate salt; as 
such, it was used to investigate its optimal concentration added to the medium. 0.025, 0.05, 0.1, 0.125, $0.15,0.175$, and $0.2 \% \mathrm{~K}_{2} \mathrm{HPO}_{4}$ and combined with $0.1 \% \mathrm{FeSO}_{4}\left(\mathrm{NH}_{4}\right)_{2} \mathrm{SO}_{4}$; the fermentation procedure was conducted at $30^{\circ} \mathrm{C}$ in $1 \mathrm{~d}$, and then $25^{\circ} \mathrm{C}$ over the next $2 \mathrm{~d}$, shaking speed of $150 \mathrm{rpm}$, and a ratio volume of medium:flask of 1:2.5 $(v / v)$.

The effect of sulfate salts and its optimal concentration added to culture medium on PG production: $\mathrm{FeSO}_{4}\left(\mathrm{NH}_{4}\right)_{2} \mathrm{SO}_{4}, \mathrm{MgSO}_{4}, \mathrm{CaSO}_{4}, \mathrm{CuSO}_{4}$, and $\left(\mathrm{NH}_{4}\right)_{2} \mathrm{SO}_{4}$ were used as sulfate salts. The medium containing $0.05 \% \mathrm{~K}_{2} \mathrm{HPO}_{4}$ and $0.1 \%$ sulfate salt, $1.5 \% \mathrm{C} / \mathrm{N}$ source were fermented at $30{ }^{\circ} \mathrm{C}$ in $1 \mathrm{~d}$, and then $25^{\circ} \mathrm{C}$ over the next $2 \mathrm{~d}$, shaking speed of $150 \mathrm{rpm}$, and a ratio volume of medium:flask of 1:2.5 $(v / v) . \mathrm{CaSO}_{4}$ was found to be the most suitable sulfate salt; as such, it was used to investigate its optimal concentration added to the medium. $0.025,0.05,0.1,0.125,0.15,0.175$, and $0.2 \% \mathrm{CaSO}_{4}$ and combined with $0.1 \% \mathrm{~K}_{2} \mathrm{HPO}_{4}$; the fermentation was conducted at $30{ }^{\circ} \mathrm{C}$ in $1 \mathrm{~d}$, and then $25{ }^{\circ} \mathrm{C}$ over the next $2 \mathrm{~d}$, shaking speed of $150 \mathrm{rpm}$, and a ratio volume of medium:flask of 1:2.5 (v/v).

The effect of some parameters on PG production: some parameters including temperature programs (activated at 20,23, 25, 27, 30, and $34{ }^{\circ} \mathrm{C}$, and then fermented at $25{ }^{\circ} \mathrm{C}$ over the next $2 \mathrm{~d}$ ), initial $\mathrm{pH}(5.15,5.65,6.15,6.65,7.15,7.65,8.15,8.65,9.15,9.65)$ and period of cultivation time $(0,1,2,3$, and $4 \mathrm{~d})$.

\subsection{Prodigiosin Quilification and Purification}

PG concentration was determined according to the method previously described by Wang et al., 2012 [36]. A mixture including $0.5 \mathrm{~mL}$ of fermented medium broth and $4 \mathrm{~mL}$ of methanol was vortexed. $2 \%(w / v)$ hydrated potassium aluminum sulfate was added into this mixture, mixed, and then centrifuged at $1400 \mathrm{~g}$ for $5 \mathrm{~min}$. The harvested supernatant was then mixed with a solution of methanol/0.5 N HCl at the ratio of $1 / 9, v / v$. The final solution optical density was measured at $535 \mathrm{~nm}$. PG purified from the culture broth was used as the standard to convert OD535 nm measurement to mass concentration via an appropriate calibration. PG was purified by the method previously described [36] with modification. The culture broth was centrifugated at $10000 \times g$ for 15 min. The supernatant was collected and mixed with ethyl acetate with the ratio 1/1. The mixture was kept in a funnel for $3 \mathrm{~h}$ and immediately shaken every $30 \mathrm{~min}$. The PG dissolved in ethyl acetate layer was collected. The PG from the cell pellet was extracted with acetone, and centrifugated at $10000 \times g$ for $15 \mathrm{~min}$. The ethyl acetate layer and acetone containing PG were mixed, concentrated by evaporation of the solvent and then dissolved in ethyl acetate for further air oven drying at $55^{\circ} \mathrm{C}$ to get dry crude PG powder. The crude PG was further purified by loading onto a silica open column (Geduran ${ }^{\circledR}$ Si 60 (Merck KGaA, Darmstadt, Germany) for column chromatography, size: 0.040-0.063 mm) and eluted with methanol in chloroform with a ratio of $0 / 10-2 / 8(v / v)$. The PG was finally isolated by thin layer chromatography (TLC) with the mobile phase system using methanol in chloroform with a ratio of $2 / 8$ $(v / v)$. After TLC separation, the lane contained PG was cut into small pieces, and methanol was used to dissolve PG. Then PG was concentrated in a rotary evaporator (IKA, Staufen, Germany) at $60{ }^{\circ} \mathrm{C}$ under vacuum. Finally, all the residue solvent was removed by keeping the sample in the oil pump in $12 \mathrm{~h}$ at $60^{\circ} \mathrm{C}$. The isolated PG was used to detect UV, MALDI-TOF MS and biological activities.

\subsection{Biological Activity Assays}

Four cancerous cell lines: A549, Hep G2, MCF-7, and WIDR were conducted to evaluate the anticancer activities. The bioassay was done according to the methods described in detail in our previous report [6]. The significant differences of anticancer activity, including inhibition (\%) and $\mathrm{IC}_{50}$ values, were analyzed with the use of Statistical Analysis Software (SAS-9.4) provided by the SAS Institute Taiwan Ltd. (Taipei City, Taiwan).

\section{Conclusions}

The current study established the novel designed medium containing $1 \% \alpha$-chitin, $0.6 \%$ casein, $0.05 \% \mathrm{~K}_{2} \mathrm{HPO}_{4}$, and $0.1 \% \mathrm{CaSO}_{4}$ for efficient biosynthesis of bioactive prodigiosin. The fermentation 
was maintained at $25^{\circ} \mathrm{C}$ for $2 \mathrm{~d}$. The prodigiosin was purified, qualified via UV and Mass. The purified prodigiosin was also evaluated for its anticancer properties. Notably, the purified PG displayed high inhibition on four cancerous cell lines. The results in this study suggest that the purified prodigiosin newly biosynthesized may be a potential candidate for cancer drugs.

Author Contributions: Conceptualization, V.B.N. and S.-L.W.; methodology, S.-L.W. and V.B.N.; software, V.B.N.; validation, S.-L.W., Y.-H.K., and T.H.N.; formal analysis, V.B.N., A.D.N., T.T.T.T., M.T.N., C.T.D., and T.N.T.; investigation, V.B.N., S.-P.C., and T.H.N.; resources, S.-L.W. and V.B.N.; data curation, S.-L.W.; writing-original draft preparation, V.B.N.; writing-review and editing, S.-L.W. and V.B.N.; visualization, V.B.N., S.-L.W.; supervision, V.B.N. and S.-L.W.; project administration, S.-L.W. and V.B.N. All authors have read and agreed to the published version of the manuscript.

Funding: This study was supported in part by a grant from the Ministry of Science and Technology, Taiwan (MOST 106-2320-B-032-001-MY3).

Acknowledgments: We express great thanks to the Department of Chemistry, Tamkang University, New Taipei City 25137; Taiwan and Division of Chinese Materia Medica Development, National Research Institute of Chinese Medicine for the kind provision of some analysis tools for this study.

Conflicts of Interest: The authors declare no conflict of interest

\section{References}

1. Nguyen, V.B.; Wang, S.L. Reclamation of marine chitinous materials for the production of $\alpha$-glucosidase inhibitors via microbial conversion. Mar. Drugs 2017, 15, 350. [CrossRef] [PubMed]

2. Liang, T.W.; Tseng, S.C.; Wang, S.L. Production and characterization of antioxidant properties of exopolysaccharides from Paenibacillus mucilaginosus TKU032. Mar. Drugs 2016, 14, 40. [CrossRef] [PubMed]

3. Liang, T.W.; Wang, S.L. Recent advances in exopolysaccharides from Paenibacillus spp.: Production, isolation, structure, and bioactivities. Mar. Drugs 2015, 13, 1847-1863. [CrossRef] [PubMed]

4. $\quad$ Liang, T.W.; Wu, C.C.; Cheng, W.T.; Chen, Y.C.; Wang, C.L.; Wang, I.L.; Wang, S.L. Exopolysaccharides and antimicrobial biosurfactants produced by Paenibacillus macerans TKU029. Appl. Biochem. Biotechnol. 2014, 172, 933-950. [CrossRef]

5. $\quad$ Liang, T.W.; Chen, W.T.; Lin, Z.H.; Kuo, Y.H.; Nguyen, A.D.; Pan, P.S.; Wang, S.L. An amphiprotic novel chitosanase from Bacillus mycoides and its application in the production of chitooligomers with their antioxidant and anti-inflammatory evaluation. Int. J. Mol. Sci. 2016, 17, 1302. [CrossRef]

6. Kuo, Y.H.; Liang, T.W.; Liu, K.C.; Hsu, Y.W.; Hsu, H.C.; Wang, S.L. Isolation and identification of a novel antioxidant with antitumor activity from Serratia ureilytica using squid pen as fermentation substrate. Mar. Biotechnol. 2011, 13, 451-461. [CrossRef]

7. Nguyen, V.B.; Nguyen, T.H.; Doan, C.T.; Tran, T.N.; Nguyen, A.D.; Kuo, Y.-H.; Wang, S.-L. Production and bioactivity-guided isolation of antioxidants with $\alpha$-glucosidase inhibitory and anti-NO properties from marine chitinous materials. Molecules 2018, 23, 1124. [CrossRef]

8. Wang, S.L.; Huang, T.Y.; Wang, C.Y.; Liang, T.W.; Yen, Y.H.; Sakata, Y. Bioconversion of squid pen by Lactobacillus paracasei subsp paracasei TKU010 for the production of proteases and lettuce enhancing biofertilizers. Bioresour. Technol. 2008, 99, 5436-5443. [CrossRef]

9. Wang, S.L.; Wang, C.Y.; Yen, Y.H.; Liang, T.W.; Chen, S.Y.; Chen, C.H. Enhanced production of insecticidal prodigiosin from Serratia marcescens TKU011 in media containing squid pen. Process Biochem. 2012, 47, 1684-1690. [CrossRef]

10. Liang, T.W.; Chen, C.H.; Wang, S.L. Production of insecticidal materials from Pseudomonas tamsuii. Res. Chem. Intermed. 2015, 41, 7965-7971. [CrossRef]

11. Wang, S.L.; Chen, S.Y.; Yen, Y.H.; Liang, T.W. Utilization of chitinous materials in pigment adsorption. Food Chem. 2012, 135, 1134-1140. [CrossRef] [PubMed]

12. Liang, T.W.; Lo, B.C.; Wang, S.L. Chitinolytic bacteria-assisted conversion of squid pen and its effect on dyes and adsorption. Mar. Drugs 2015, 13, 4576-4593. [CrossRef] [PubMed]

13. Nguyen, V.B.; Nguyen, A.D.; Wang, S.L. Utilization of fishery processing by-product squid pens for $\alpha$-glucosidase inhibitors production by Paenibacillus sp. Mar. Drugs 2017, 15, 274. [CrossRef] [PubMed]

14. Doan, C.T.; Tran, T.N.; Nguyen, M.T.; Nguyen, V.B.; Nguyen, A.D.; Wang, S.-L. Anti- $\alpha$-glucosidase activity by a protease from Bacillus licheniformis. Molecules 2019, 24, 691. [CrossRef] [PubMed] 
15. Wang, S.L.; Su, Y.C.; Nguyen, V.B.; Nguyen, A.D. Reclamation of shrimp heads for the production of $\alpha$-glucosidase inhibitors by Staphylococcus sp. TKU043. Res. Chem. Intermed. 2018, 44, 4929-4937. [CrossRef]

16. Hsu, C.H.; Nguyen, V.B.; Nguyen, A.D.; Wang, S.L. Conversion of shrimp heads to $\alpha$-glucosidase inhibitors via co-culture of Bacillus mycoides TKU040 and Rhizobium sp. TKU041. Res. Chem. Intermed. 2017, 44, 4597-4607. [CrossRef]

17. Nguyen, V.B.; Nguyen, A.D.; Kuo, Y.-H.; Wang, S.-L. Biosynthesis of $\alpha$-glucosidase inhibitors by a newly isolated bacterium, Paenibacillus sp. TKU042 and Its effect on reducing plasma glucose in a mouse model. Int. J. Mol. Sci. 2017, 18, 700. [CrossRef]

18. Nguyen, V.B.; Wang, S.L. Production of potent antidiabetic compounds from shrimp head powder via Paenibacillus conversion. Process Biochem. 2019, 76, 18-24. [CrossRef]

19. Liang, T.W.; Chen, S.Y.; Chen, Y.C.; Chen, Y.C.; Yen, Y.H.; Wang, S.L. Enhancement of prodigiosin production by Serratia marcescens TKU011 and its insecticidal activity relative to food colourants. J. Food Sci. 2013, 78, 1743-1751. [CrossRef]

20. Furstner, A. Chemistry and biology of roseophilin and the prodigiosin alkaloids: A survey of the last 2500 years. Chem. Int. Ed. Engl. 2003, 42, 3582-3603. [CrossRef]

21. Cerdeno, A.M.; Bibb, M.J.; Challis, G.L. Analysis of the prodiginine biosynthesis gene cluster of Streptomyces coelicolor A3(2): New mechanisms for chain initiation and termination in modular multienzymes. Chem. Biol. 2001, 8, 817-829. [CrossRef]

22. Samrot, A.V.; Chandana, K.; Senthilkumar, P.; Narendra, K.G. Optimization of prodigiosin production by Serratia marcescens SU-10 and evaluation of its bioactivity. Int. Res. J. Biotechnol. 2011, 2, 128-133.

23. de Casullo Araújo, H.W.; Fukushima, K.; Campos Takaki, G.M. Prodigiosin production by Serratia marcescens UCP 1549 using renewable-resources as a low-cost substrate. Molecules 2010, 15, 6931-6940. [CrossRef] [PubMed]

24. Gulani, C.; Bhattacharya, S.; Das, A. Assessment of process parameters influencing the enhanced production of prodigiosin from Serratia marcescens and evaluation of its antimicrobial, antioxidant and dyeing potentials. Malays. J. Microbiol. 2012, 8, 116-122.

25. Nakamura, K.; Kitamura, K. Process for Preparation of Prodigiosin. U.S. Patent 4,266,028A, 5 May 1981.

26. Giri, A.V.; Anandkumar, N.; Muthukumaran, G.; Pennathur, G. A novel medium for the enhanced cell growth and production of prodigiosin from Serratia marcescens isolated from soil. BMC Microbiol. 2004, 4, 11-18. [CrossRef]

27. Shahitha, S.; Poornima, K. Enhanced production of prodigiosin production in Serratia marcescens. J. Appl. Pharm. Sci. 2012, 2, 138-140. [CrossRef]

28. Wang, S.L.; Kao, D.Y.; Wang, C.L.; Yen, Y.H.; Chern, M.K.; Chen, Y.H. A solvent stable metalloprotease produced by Bacillus sp. TKU004 and its application in the deproteinization of squid pen for beta-chitin preparation. Enzyme Microb. Technol. 2006, 39, 724-731. [CrossRef]

29. Wei, Y.H.; Chen, W.C. Enhanced production of prodigiosin-like pigment from Serratia marcescens SMdeltaR by medium improvement and oil-supplementation strategies. J. Biosci. Bioeng. 2005, 99, 616-622. [CrossRef]

30. Wei, Y.H.; Yu, W.J.; Chen, W.C. Enhanced undecylprodigiosin production from Serratia marcescens SS-1 by medium formulation and amino-acid supplementation. J. Biosci. Bioeng. 2005, 100, 466-471. [CrossRef]

31. Wang, X.; Tao, J.; Wei, D.; Shen, Y.; Tong, W. Development of an adsorption procedure for the direct separation and purification of prodigiosin from culture broth. Biotechnol. Appl. Biochem. 2004, 40, 277-280.

32. Solé, M.; Rius, N.; Francia, A.; Lorén, J.G. The effect of $\mathrm{pH}$ on prodigiosin production by non-proliferating cells of Serratia marcescens. Lett. Appl. Microbiol. 1994, 19, 341-344. [CrossRef] [PubMed]

33. Lin, C.; Jia, X.; Fang, Y.; Chen, L.; Zhang, H.; Lin, R.; Chen, J. Enhanced production of prodigiosin by Serratia marcescens FZSF02 in the form of pigment pellets. Electron. J. Biotechnol. 2019, 40, 58-64. [CrossRef]

34. Sumathi, C.; MohanaPriya, D.; Swarnalatha, S.; Dinesh, M.G.; Sekaran, G. Production of prodigiosin using tannery fleshing and evaluating its pharmacological effects. SCI World J. 2014, 2014, 290327. [CrossRef] [PubMed]

35. Holly, S.; Matthew, C.; Lee, E.; George, P.C.S. Phosphate availability regulates biosynthesis of two antibiotics, prodigiosin and carbapenem, in Serratia via both quorum-sensing-dependent and -independent pathways. Mol. Microbiol. 2003, 47, 303-320. 
36. Doan, C.T.; Tran, T.N.; Nguyen, V.B.; Nguyen, A.D.; Wang, S.-L. Reclamation of marine chitinous materials for chitosanase production via microbial conversion by Paenibacillus macerans. Mar. Drugs 2018, 16, 429. [CrossRef]

37. Arivizhivendhan, K.V.; Mahesh, M.; Boopathy, R.; Swarnalatha, S.; Regina Mary, R.; Sekaran, G. Antioxidant and antimicrobial activity of bioactive prodigiosin produces from Serratia marcescens using agricultural waste as a substrate. J. Food Sci. Technol. 2018, 55, 2661. [CrossRef]

38. Yenkejeh, R.A.; Sam, M.R.; Esmaeillou, M. Targeting survivin with prodigiosin isolated from cell wall of Serratia marcescens induces apoptosis in hepatocellular carcinoma cells. Hum. Exp. Toxicol. 2017, 36, 402-411. [CrossRef]

39. Chen, J.; Li, Y.; Liu, F.; Hou, D.-X.; Xu, J.; Zhao, X.; Yang, F.; Feng, X. Prodigiosin promotes Nrf2 activation to inhibit oxidative stress induced by microcystin-LR in HepG2 cells. Toxins 2019, 11, 403. [CrossRef]

40. Orlikova, B.; Legrand, N.; Panning, J.; Dicato, M.; Diederich, M. Anti-inflammatory and anticancer drugs from nature. Cancer Res. Treat. 2014, 159, 123-143.

41. Li, D.; Liu, J.; Wang, X.; Kong, D.; Du, W.; Li, H.; Hse, C.-Y.; Shupe, T.; Zhou, D.; Zhao, K. Biological potential and mechanism of prodigiosin from Serratia marcescens subsp. lawsoniana in human choriocarcinoma and prostate cancer cell lines. Int. J. Mol. Sci. 2018, 19, 3465.

42. Dalili, D.; Fouladdel, S.; Rastkari, N.; Samadi, N.; Ahmadkhaniha, R.; Ardavan, A.; Azizi, E. Prodigiosin, the red pigment of Serratia marcescens, shows cytotoxic effects and apoptosis induction in HT-29 and T47D cancer cell lines. Nat. Prod. Res. 2011, 26, 2078-2083. [PubMed]

43. Perez-Tomas, R.; Montaner, B.; Llagostera, E.; Soto-Cerrato, V. The prodigiosins, proapoptotic drugs with anticancer properties. Biochem. Pharmacol. 2003, 66, 1447-1452. [CrossRef]

44. Nguyen, V.B.; Wang, S.L.; Nguyen, T.H.; Nguyen, T.H.; Trinh, T.H.T.; Nong, T.T.; Nguyen, T.U.; Nguyen, V.N.; Nguyen, A.D. Reclamation of rhizobacteria newly isolated from black pepper plant roots as potential biocontrol agents of root-knot nematodes. Res. Chem. Intermed. 2019. [CrossRef]

(C) 2019 by the authors. Licensee MDPI, Basel, Switzerland. This article is an open access article distributed under the terms and conditions of the Creative Commons Attribution (CC BY) license (http://creativecommons.org/licenses/by/4.0/). 